\title{
ATUAÇÃO DO PSICÓLOGO NA UNIDADE DE TERAPIA INTENSIVA: uma revisão sistemática
}

\author{
Walmy Porto da Silva ${ }^{1}$ \\ Isabel Cristina Oliveira Gomes ${ }^{2}$
}

\section{RESUMO}

INTRODUÇÃO: A inserção da Psicologia Intensiva nas Unidade de Terapia Intensiva (UTI) tem o objetivo de oferecer suporte ao paciente crítico e à sua família e apoio à equipe interdisciplinar no sentido de proporcionar a todos uma percepção das dimensões biopsicossociais da saúde, do adoecer e da morte humanizados. A atuação do psicólogo intensivista se fundamenta na ampla percepção que este deve ter sobre os aspectos emocionais capazes de comprometer o estado do paciente, que encontram-se envolvidos os aspectos sociais, emocionais, culturais e familiares e que podem contribuir para ajudar ou dificultar o seu enfrentamento diante da hospitalização. OBJETIVO: Analisar a atuação do psicólogo na Unidade de Terapia Intensiva. MÉTODO: O estudo foi uma revisão sistemática. As fontes foram artigos científicos publicados em Português no período de 2002 a 2017. Os artigos científicos respeitantes ao tema foram buscados por meio de palavras-chave como "Psicólogo", Psicologia Hospitalar" "Unidade de Terapia Intensiva". Nas bases Pepsic, Scielo e Bireme. RESULTADOS: A Psicologia Intensiva surge do atendimento psicológico ao paciente crítico, vez que a internação numa UTI gera sentimentos de ansiedade e temor da morte no paciente e em seus familiares. Para acompanhar o doente, sua família e os profissionais envolvidos em seu tratamento, os psicólogos devem ter habilidades que permitam interagir com as pessoas em condições especiais, de forma a associar conhecimentos que transcendem sua própria disciplina. DISCUSSÃO: Alguns dos objetivos da atuação do Psicólogo na Terapia Intensiva são: trabalhar a relação emocional do paciente com a doença e necessidade de permanência na UTI, orientar o paciente durante a

\footnotetext{
${ }^{1}$ Acadêmica do curso de psicologia da Faculdade Patos de Minas - FPM. E-mail de contato: walmyporto@yahoo.com.br

${ }^{2}$ Docente do departamento de psicologia da Psicologia da Faculdade Patos de Minas - FPM.
} 
internação, avaliando seu quadro psíquico e intercorrências emocionais e favorecer a expressão não verbal do paciente entubado ou sem possibilidade de comunicação verbal. CONSIDERAÇÕES FINAIS: O psicólogo pode atuar junto aos atores envolvidos no processo de hospitalização na UTI com o fim de orientar e informar rotinas da Unidade, horário de visita; informar ao paciente sobre os fatos que acontecem fora da UTI, mesmo se o paciente estiver inconsciente; e motivar o contato do paciente com a família e equipe, de modo a facilitar a comunicação entre as partes envolvidas.

Palavras-chave: Psicologia; Psicologia Intensiva; Unidade de Terapia Intensiva. 